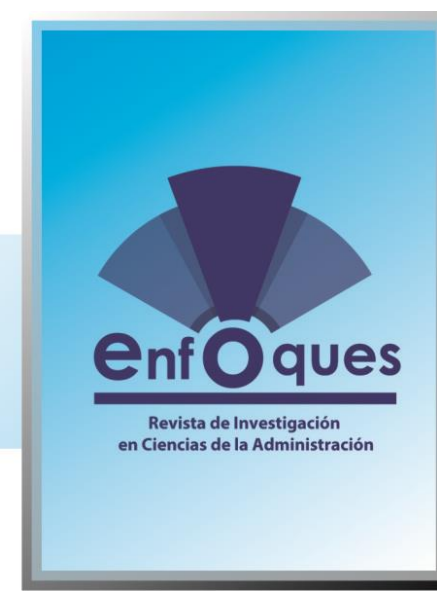

\title{
Curriculo de Autores
}

\section{Damarick Diomara Pacheco Barrera.}

Ingeniero Mecánico, egresado de la Universidad del Zulia. Magister Scientiarum en Gerencia de Operaciones. Universidad del Zulia.

\section{Jelipe Antonio Bastidas Jerán.}

Doctor en Ciencias Sociales-Estudios. Doctor en Ciencias de la Educación. Magíster en Investigación Educativa. Especialista en Educación y Politólogo. Director-Editor de la Revista Estudios Culturales y Profesor Titular de la Universidad de Carabobo. Tutor de investigación y asesor metodológico. Identificador Orcid: 0000-0002-4867-0711.

\section{gesús Gabriel Villasmil Jarcos.}

Ingeniero Mecánico, egresado de la Universidad del Zulia, Venezuela. Psicólogo Universidad de Yacambú. Maestría en Gerencia de Proyectos Industriales, Universidad Rafael Belloso Chacín, Venezuela.

\section{Oita Jabiola Gómez Japia.}

Ingeniero Comercial. Egresada de la Universidad Privada Domingo Savio. Capacitación de Principios de Autosuficiencia Aplicada, realizado el 29 de mayo de 2016. Taller "Ley SAFCO 1178 Gobernabilidad" como se diseñan y gestionan las políticas en el Estado Plurinacional de Bolivia, realizado el 5 y 6 de mayo de 2017 en la ciudad de Cochabamba. Congreso Latinoamericano de Ciencias Económicas, Financieras, Contables, Comerciales y Administrativas, realizado el 5 y 6 de mayo del 2017 en la ciudad de Cochabamba "el futuro de la publicidad" realizado el 19 de mayo del 2017 en la ciudad de Sucre "Neuromarketing" realizado el 20 de mayo del 2017 en la ciudad de Sucre. 